\title{
Is it feasible to assess self-reported quality of life in individuals who are deaf and have intellectual disabilities?
}

\author{
Johannes Fellinger ${ }^{1,2,3} \cdot$ Magdalena Dall $^{1,2} \cdot$ Joachim Gerich $^{4} \cdot$ Maria Fellinger $^{2} \cdot$ Katharina Schossleitner $^{1,2}$. \\ William Joseph Barbaresi ${ }^{5}$. Daniel Holzinger ${ }^{1,2,6}$
}

Received: 3 March 2020 / Accepted: 1 September 2020 / Published online: 14 September 2020

(c) The Author(s) 2020

\begin{abstract}
Purpose There is consensus that Quality of Life (QOL) should be obtained through self-reports from people with intellectual Disability (ID). Thus far, there have been no attempts to collect self-reported QOL from people who are deaf and have ID. Methods Based on an established short measure for QOL (EUROHIS-QOL), an adapted easy-to-understand sign language interview was developed and applied in a population $(n=61)$ with severe-to-profound hearing loss and mild-to-profound ID. Self-reports were conducted at two time points $\left(t_{1}\right.$ and $\left.t_{2}\right), 6$ months apart. The Stark QOL, an established picture-based questionnaire, was also obtained at $t_{2}$ and three Proxy ratings of QOL (from caregivers) were conducted for each participant at $t_{1}$. Results Self-reported QOL was successfully administered at both time points for 44 individuals with mild and moderate ID (IQ reference age between 3.3 and 11.8 years).

The self-reports showed sufficient test-retest reliability and significant correlations with the Stark QOL. As anticipated, self-reported QOL was higher than proxy-reported QOL. Test-retest reliability and internal consistency were good for selfreported QOL.

Conclusion Reliable and valid self-reports of QOL can be obtained from deaf adults with mild-moderate ID using standard inventories adapted to the linguistic and cognitive level of these individuals.
\end{abstract}

Keywords Quality of life $\cdot$ Intellectual disability $\cdot$ Deafness $\cdot$ Self-report $\cdot$ Sign language

\section{Introduction}

Since the publication of the Convention on the Rights of Persons with Disabilities [1], quality of life has proved to be a useful construct to drive progress towards equity, empowerment, and self-determination [2].

However, obtaining information on Quality of Life directly from people with intellectual disabilities (ID) has been shown to be challenging. Prior studies highlight barriers including language and cognitive function, response bias, and theory of mind [3-6] that are even more relevant in persons who are deaf and have ID [7]. There is consensus that individuals with ID should be directly involved in the measurement of their QOL [8-10]. For this purpose, strategies such as simplifying questions and response options and the use of supportive visuals are required [11]. Proxy ratings are regarded as an important source of additional information, especially in subjects where self-reports are not feasible $[8,9,12]$. Although it is assumed that close relatives or caregivers can provide information that is comparable to 
the responses which the individual would give [13-18], there are diverging findings on the congruence between self- and proxy-ratings. The majority of studies report higher selfrated QOL scores than proxy-rated QOL scores [10, 19-21], whereas Schwartz and Rabinovitz [17] found the opposite.

Although hearing loss is a common condition in people with ID, with prevalence rates ranging from 30 to $46 \%$ [22, 23], we were not able to identify research on assessment methodology of QOL in adults who are deaf and have an intellectual disability. In this population, language deprivation often presents another obstacle to accurate measurement of QOL [24].

In the present study, we aim to develop a reliable and valid procedure to measure self-reported QOL in individuals who are deaf and have ID.

\section{Methods}

\section{Participants}

All participants are enrolled in one of three specialized therapeutic living communities in Austria. These communities are characterized by the constant use of individually adapted sign language and focus on the development of self-determination and social relationships. The entire staff is competent in signed communication; $20 \%$ of personnel are themselves deaf. There is a staff-to-client ratio of 1:4. At the time of the study, 61 individuals with severe-to-profound prelingual hearing loss and mild-to-profound ID, aged between 19 and 74 years, have been included in the programs for periods ranging from 6 months to 20 years. Among these 61 people, 13 participate only in the workshop facilities but are not living in the therapeutic residential facilities.

\section{Measures}

\section{Intellectual functioning}

As cognitive levels of the population varied between mild and profound intellectual disability, two versions of the Snijders-Oomen Non-verbal Intelligence Scale were used: SON-R 6-40 [25] for individuals with an IQ reference age of 6 years or older and the SON-R 21/2-7 [26] for the remaining participants. As the SON-R 2 1 1/2-7 does not report IQ scores, IQ reference age is reported for all participants.

\section{QOL measures}

All Quality-of-Life measures used are based on the EUROHIS-QOL 8-item index (European Health Interview Surveys [27]). It consists of eight questions that are also included in both the WHOQOL-100 questionnaire [28-30] and the
WHOQOL-BREF (an abbreviated version of the WHOQOL 100 with 26 items; [30-32]. For the WHOQOL-BREF, a sign language version has been previously developed that is designed for full self-administration and tested in a large deaf population [33].

The EUROHIS-QOL includes two questions representing each of the four domains (physical, psychological, social, and environmental) and produces an overall QOL score. Responses are given on a five-point Likert scale. The EUROHIS-QOL score is computed as the mean score across the eight items on the measure, with scores ranging from 1 (worst QOL) to 5 (best QOL) for each item. The EUROHISQOL has been assessed across various settings and countries [27]. A general population study in Germany showed good reliability as well as construct validity [34].

\section{Self-reports-EUROHIS-QOL}

For our study sample, the EUROHIS-QOL was translated and adapted into an easy-to-understand sign language version (EUROHIS-QOL ESL). The EUROHIS-QOL was adapted to the needs of individuals with ID and limited sign language skills. We followed the international suggestions for translation of quality-of-life measures [35, 36] and those for easy-to-understand (easy-to-read) language [37, 38], as well as recommendations for translation from spoken into signed languages [39]. A deaf professional working in education and care and a sign competent neuropsychiatrist reviewed the contents of the German EUROHIS-QOL and of the sign language version of the WHOQOL-BREF [33], and developed a first draft of an easy-to-understand sign language version. A revised second version included input from a linguist, a psychologist, and four care professionals, all fluent in Austrian sign language. This version was video recorded with a native signer, back translated by a professional Austrian sign language interpreter, and piloted with three participants by presenting the videos of the signed questions. Questions were answered using a five-point visually based Likert scale with smileys. As recommended by others $[4,40]$, the Likert scale was explained and training questions were offered immediately before the questions, to ensure that respondents understood how to respond to the items. This pilot showed that, contrary to prior experience in a general population of individuals who are deaf [33], computer-based self-administration was not possible in this population of persons with deafness and ID. Therefore, the EUROHIS-QOL ESL was subsequently administered as a standardized face-to-face interview. Interviewers were provided a video template and a written interview guideline to ensure the highest possible standardized administration of the EUROHIS-QOL ESL and to prevent translations on the fly [41]. This interview guideline offered the flexibility to add scripted examples to maximize understanding of the 
contents and to ensure higher response rates. This approach has also been used in the previous research studies [4, 42]. As with the EUROHIS-QOL, the EUROHIS-QOL ESL score is computed as the mean score across the eight items, ranging from 1 (worst QOL) to 5 (best QOL). The interviewers rated the participants' comprehension of each question on a three-point Likert scale [good (three points), uncertain (two points), and no comprehension (one point)]. The maximum possible score for comprehension of the instrument was, therefore, 24 points. Participants with comprehension scores less than 16 points were excluded from this study. We identified a subgroup of participants with good comprehension (22-24 points, maximum of two questions rated as uncertain) to evaluate the instrument in persons deemed capable of understanding the EUROHIS-QOL ESL items.

\section{Proxy-ratings-EUROHIS-QOL}

Professional caregivers were asked to answer questions on the proxy questionnaire (EUROHIS-QOL) from the participants' perspective, as described by Pickard and Knight [43] and McPhail et al. [44]. For participants living at the therapeutic community, there are three separate proxy ratings (proxy 1 and proxy 2 from the therapeutic residential facility and proxy 3 from the workshop facility). For the 13 participants, who were only involved in the workshop facilities, only the rating from the caregiver (proxy 3 ) in the workshop facility was obtained. In total, 66 staff members (73\% female; mean age 41 years) completed the EUROHISQOL proxy questionnaire.

\section{Validation of QOL measures}

For the validation of the EUROHIS-QOL ESL the Stark Quality of Life Questionnaire (Stark QOL; [45] was administered. The Stark QOL uses short questions that were translated into easy-to-understand sign language, and descriptive pictures as response options. Three items of the Stark QOL with respect to mood, energy, and social contact were selected; these three items can be combined into the Stark QOL mental component with a score range from 0 (worst QOL) to 100 (best QOL). One possible limitation of this approach is the risk of mono- or common-method bias [46]. This may inflate the correlation between EUROHIS-QOL ESL and the Stark measure by applying a similar method of data collection for both constructs. Higher risks for method bias are assumed for measures addressing cognitive and emotional states [47] where acquiescence or the use or avoidance of extreme response categories [48] has been observed.

Therefore, an additional experimental validation approach was employed, using a different mode of data collection that we term "Light response". Respondents rated their general well-being by adjusting the brightness of a light bulb with the help of a five-level controller to express their perception of their QOL, where complete darkness (level 1) corresponded to the lowest QOL and the brightest level (level 5) corresponded to the best QOL.

\section{Procedure}

Data collection took place between September 2017 and March 2018. To obtain test-retest reliability, the self-report interviews were conducted twice $\left(t_{1}\right.$ and $\left.t_{2}\right)$, with 6 months in between, by one care professional per site (two deaf and one hearing fluent in sign language). The interviewers were not directly involved in care and did not act as a proxy in this study, but knew the participants well enough to successfully conduct the interviews. The non-involvement in care was considered important, in order for the participants not to feel pressured to give answers that they thought would be satisfactory for the interviewer. Nevertheless, it was also important for the interviewers to understand the participants' way of communication. Validation measures were obtained at $t_{2}$ only. Proxy ratings of QOL were conducted at $t_{1}$ only.

\section{Statistical analysis}

Intraclass correlation coefficient (ICC) was used to estimate test-retest reliability of self-reported EUROHIS-QOL ESL and agreement between self- and proxy ratings. As the proxy raters in our study were fixed (e.g., not based on a random sample) and the agreement is assumed for any randomly selected participant, ICC's were computed on the basis of a two-way mixed ANOVA model (ICC model three, [49]. Moreover, as our analysis focuses on the comparison of one rating per rater for each case, the ICC form is one (ICC for single measures). Therefore, the computed coefficients are of the type $\operatorname{ICC}(3,1)[50]$.

ICC analysis allows differentiation of the degree of agreement into "absolute agreement" (identical rating) or "consistency agreement" (i.e., higher ratings of one rater correspond to higher ratings of the other and vice versa, but both ratings are not necessarily identical). A high ICC based on consistency agreement-which is in most cases identical to Pearson's correlation-indicates high consistency of ratings which is invariant with respect to linear transformations. Typically, the ICC based on absolute agreement will be smaller than the ICC based on consistency agreement. Consequently, larger differences between both types of ICCs indicate that systematic under- or overestimation of one rater compared to the other. $\operatorname{ICC}(3,1)$ is also used as an estimator of test-retest reliability [50, p.131]. Moreover, reliability of proxy- and self-reports (separately computed for measures administered at $t_{1}$ and $t_{2}$ ) is estimated on the basis of internal consistency (Cronbachs Alpha). According 
to Fleiss [51] and Trevethan [50], ICC values $<0.40$ can be classified as poor and values between 0.40 and 0.75 as fairto-good agreement for non-clinical applications. Values of Cronbachs Alpha $>0.7$ are classified as sufficient and values $>0.8$ as good internal consistency [52].

$T$ test for paired samples was used to compare mean QOL scores of self- and proxy-ratings.

\section{Ethics}

The study was approved by the ethics committee at the hospital Barmherzige Brüder Linz, Austria.

\section{Results}

\section{Participants}

Among the 61 eligible persons, 12 persons could not participate at either time point due to a lack of basic understanding. For another eight persons, responses were obtained at only one time point due to organizational or personal reasons (e.g., longer hospital stays and refusal to participate). Complete data at both time points are available for 41 individuals (67\% of total sample), 25 of whom (41\% of total sample) were in the subgroup of those with good comprehension. In total, there were 47 (77\%) complete responses to the EUROHIS-QOL ESL at $t_{1}$ and $43(70 \%)$ complete responses at $t_{2}$.

IQ reference age is available for 57 persons. The missing data are from persons who either refused IQ testing or for whom testing resulted in an IQ reference age below 2 years. Descriptive information regarding age, sex, and IQ reference age of the study population is given in Table 1. Comparison of the mean EUROHIS-QOL ESL scores of those individuals (1) without complete self-reports, (2) complete self-reports but limited comprehension, and (3) complete self-reports and good comprehension shows significant differences with respect to IQ reference age.

As is apparent from Table 1, the IQ reference age level of the subpopulation with complete self-reported data $(n=41)$ is higher compared to the non-participants $(n=16)$. The range of the IQ reference age in the total population is between 2.8 and 11.8 years, whereas the range in the subpopulation with complete data is between 3.3 and 11.8. Being a member of the subgroup with complete self-reported data is significantly correlated with IQ reference age ( $r=0.32 ; p=0.017)$. Good comprehension of the responders is also significantly correlated with IQ reference age $(r=0.33 ; p=0.036)$. Differences in age and sex between the subsample of responders with complete data, as well as the subsample with good comprehension compared to the other participants are not significant $(p>0.05)$. For 9 of the 12 participants who could not participate due to a lack of basic understanding, mean IQ reference age was 4.28 years $(\mathrm{SD}=0.85)$, mean chronological age was 45.7 years $(\mathrm{SD}=19.3 ; n=12)$, and $25 \%$ were female.

Results for the QOL measures and the validation measures (Stark QOL and Light Response) for the sample with self-reports available for both time points are shown in Table 2.

QOL scores and scores on validation measures did not differ between participants with good comprehension versus those with limited comprehension (Table 2).

\section{Reliability estimates of EUROHIS-QOL ESL}

Table 3 shows reliability estimations for self-reported QOL data (test-retest and internal consistency). Test-retest reliability based on consistency measures (ICC for consistence) as well as based on absolute agreement of QOL scores between both time points is good ( $>0.7)$. Similarly, with respect to Cronbachs Alpha, sufficient internal consistency at both time points with values higher than 0.7 is estimated. Reliability estimates for the subsample with good comprehension $(\geq 0.8)$ indicate good reliability.

\section{Reliability of proxy measures}

Table 3 also shows ICC measures for consistency and absolute agreement between the proxy-rated QOL scores. The mean ICC coefficient for consistency as well as for absolute agreement of all three pairs of proxy ratings was 0.61 (range between 0.56 and 0.68 ) which can be classified as fair-to-good agreement. Also, sufficient to good internal

Table 1 Demographics

\begin{tabular}{llllllll}
\hline & Total $(n$ 61) & $n$ & $\begin{array}{l}\text { Subsample with complete self- } \\
\text { reports at both time points }(n \text { 41) }\end{array}$ & $n$ & $\begin{array}{l}\text { Subsample with good } \\
\text { comprehension }(n \text { 25) }\end{array}$ & $n$ & $p$ value Anova \\
\hline Age in years $M(\mathrm{SD})$ & $45.67(18.31)$ & 61 & $46.93(18.07)$ & 41 & $45.88(17.22)$ & 25 & 0.657 \\
Sex (female \%) & 37.7 & 61 & 43.9 & 41 & 44.0 & 25 & 0.372 \\
IQ reference age in & $6.45(2.14)$ & 57 & $6.87(2.08)$ & 41 & $7.41(1.80)$ & 25 & 0.006 \\
years $M$ (SD) & & & & & & & \\
\hline
\end{tabular}

${ }^{a}$ Anova comparing age, sex and IQ reference age (means) of excluded individuals, individuals with complete responses but limited comprehension, and individuals with complete responses and good comprehension 
Table 2 Descriptive information for the QOL and validation measures

\begin{tabular}{|c|c|c|c|c|c|}
\hline & $\begin{array}{l}\text { Subsample with complete self- } \\
\text { reports at both time points }\end{array}$ & $n$ & $\begin{array}{l}\text { Subsample with good } \\
\text { comprehension }\end{array}$ & $n$ & $p$ value $^{\mathrm{a}}$ \\
\hline EUROHIS-QOL ESL Self-report score $t_{1} M$ (SD) & $4.23(0.65)$ & 41 & $4.37(0.65)$ & 25 & 0.086 \\
\hline EUROHIS-QOL ESL Self-report score $\mathrm{t}_{2} \mathrm{M}(\mathrm{SD})$ & $4.27(0.66)$ & 41 & $4.30(0.73)$ & 25 & 0.699 \\
\hline EUROHIS-QOL score Proxy $1 t_{1} M$ (SD) & $3.88(0.61)$ & 29 & $3.83(0.67)$ & 18 & 0.648 \\
\hline EUROHIS-QOL score Proxy $2 t_{1} M$ (SD) & $3.70(0.75)$ & 29 & $3.58(0.79)$ & 18 & 0.283 \\
\hline EUROHIS-QOL score Proxy $3 t_{1} M$ (SD) & $3.82(0.45)$ & 41 & $3.85(0.43)$ & 25 & 0.571 \\
\hline EUROHIS-QOL score Proxy mean $t_{1} M$ (SD) & $3.81(0.52)$ & 41 & $3.83(0.54)$ & 25 & 0.835 \\
\hline Stark QOL score self-report $t_{2} M(\mathrm{SD})$ & $73.64(29.75)$ & 41 & $71.10(29.77)$ & 25 & 0.502 \\
\hline Light Response & $4.11(1.21)$ & 36 & $3.86(1.36)$ & 22 & 0.127 \\
\hline
\end{tabular}

${ }^{\mathrm{a}} p$ value for differences of means between the group with good versus limited questionnaire comprehension $(t$ test $)$

Table 3 Reliability estimation of self and proxy reports

\begin{tabular}{lll}
\hline & Total sample & $\begin{array}{l}\text { Subsample good } \\
\text { comprehension }\end{array}$ \\
\hline Self-reports: test-retest & & \\
ICC $(3,1)$, consistency & 0.75 & 0.83 \\
ICC (3,1), absolute & 0.75 & 0.83 \\
Self reports: internal consistency & & \\
Cronbachs Alpha $t_{1}$ & 0.78 & 0.81 \\
Cronbachs Alpha $t_{2}$ & 0.78 & 0.80 \\
Proxy reports: agreement & & \\
$\quad$ Mean ICC(3,1), consistency & 0.61 & \\
$\quad$ Mean ICC(3,1), absolute & 0.61 & \\
Proxy reports: internal consistency & & \\
Mean Cronbachs alpha & 0.80 & \\
\hline
\end{tabular}

consistency of the three proxy measures was confirmed (mean Cronbachs Alpha across all three proxy ratings is 0.80 with a range between 0.72 and 0.87 ).

\section{Estimation of validity}

Table 4 shows the correlations of self- and proxy measures with the Stark-questionnaire score and the Light response (both measured at $t_{2}$ ). Significant positive correlations between self-reported EUROHIS-QOL ESL at both time points and Stark-questionnaire score are confirmed. Correlations are somewhat higher for self-reports measured at $t_{2}$ and for the subsample with good comprehension. In contrast, none of the proxy QOL measures, taken at time point 1, are significantly correlated with the Stark QOL measure. The correlations between self-reported EUROHIS-QOL ESL scores at $t_{1}$ and the Light Response are not significant. However, at $t_{2}$, a marginally significant positive correlation $(p<0.10)$ for the total sample and a significant positive correlation $(p<0.05)$ for the subsample with good comprehension were found. As with the Stark QOL, no significant correlations between Light Response and the proxy QOL scores were found.
Table 4 Correlations of selfand proxy reports with Stark QOL and light response

\begin{tabular}{|c|c|c|c|c|c|c|c|c|}
\hline & \multicolumn{4}{|l|}{ Stark QOL } & \multicolumn{4}{|l|}{ Light response } \\
\hline & \multicolumn{2}{|c|}{$\begin{array}{l}\text { Total sample } \\
\text { with complete } \\
\text { responses at both } \\
\text { time points }\end{array}$} & \multicolumn{2}{|c|}{$\begin{array}{l}\text { Subsample with } \\
\text { good rated compre- } \\
\text { hension }\end{array}$} & \multicolumn{2}{|c|}{$\begin{array}{l}\text { Total sample with } \\
\text { complete responses } \\
\text { at both time points }\end{array}$} & \multicolumn{2}{|c|}{$\begin{array}{l}\text { Subsample with } \\
\text { good rated com- } \\
\text { prehension }\end{array}$} \\
\hline & $r(p)$ & $n$ & $r(p)$ & $n$ & $r(p)$ & $n$ & $r(p)$ & $n$ \\
\hline Qol8 self-report $t_{1}$ & $0.33(0.038)$ & 41 & $0.52(0.007)$ & 25 & $0.16(0.343)$ & 36 & $0.20(0.376)$ & 22 \\
\hline Qol8 self-report $t_{2}$ & $0.42(0.007)$ & 41 & $0.71(<0.001)$ & 25 & $0.31(0.067)$ & 36 & $0.44(0.042)$ & 22 \\
\hline Qol8 proxy 1 & $0.23(0.233)$ & 29 & $0.31(0.216)$ & 18 & $0.11(0.596)$ & 25 & $0.26(0.348)$ & 15 \\
\hline Qol8 proxy 2 & $0.27(0.151)$ & 29 & $0.51(0.031)$ & 18 & $-0.01(0.963)$ & 25 & $0.04(0.882)$ & 15 \\
\hline Qol8 proxy 3 & $0.17(0.289)$ & 41 & $0.43(0.034)$ & 25 & $-0.06(0.740)$ & 36 & $0.07(0.772)$ & 22 \\
\hline
\end{tabular}


Table 5 Agreement between self- and proxy-reports

\begin{tabular}{|c|c|c|c|c|}
\hline & Proxy 1 , self & Proxy 2 , self & Proxy 3 , self & Mean ICC \\
\hline \multicolumn{5}{|c|}{$t_{1}$ Total sample of responders } \\
\hline $\operatorname{ICC}(3,1)$ consistency & 0.31 & 0.39 & 0.23 & 0.31 \\
\hline $\operatorname{ICC}(3,1)$ absolute & 0.26 & 0.29 & 0.19 & 0.25 \\
\hline$p(\mathrm{ICC})$ & 0.051 & 0.017 & 0.068 & \\
\hline Mean difference $(p)$ & $0.41(0.007)$ & $0.60(<0.001)$ & $0.41(0.001)$ & \\
\hline$n$ & 29 & 29 & 41 & \\
\hline \multicolumn{5}{|c|}{$t_{1}$ Subsample good comprehension } \\
\hline ICC $(3,1)$ consistency & 0.42 & 0.42 & 0.40 & 0.41 \\
\hline $\operatorname{ICC}(3,1)$ absolute & 0.34 & 0.28 & 0.28 & 0.30 \\
\hline$p(\mathrm{ICC})$ & 0.036 & 0.038 & 0.021 & \\
\hline Mean difference $(p)$ & $0.52(0.008)$ & $0.77(0.001)$ & $0.52(<0.001)$ & \\
\hline$n$ & 18 & 18 & 25 & \\
\hline \multicolumn{5}{|c|}{$t_{2}$ Total sample of responders } \\
\hline $\operatorname{ICC}(3,1)$ consistency & 0.45 & 0.59 & 0.39 & 0.48 \\
\hline $\operatorname{ICC}(3,1)$ absolute & 0.37 & 0.42 & 0.30 & 0.36 \\
\hline$p(\mathrm{ICC})$ & 0.006 & $<0.001$ & 0.005 & \\
\hline Mean difference $(p)$ & $0.45(0.001)$ & $0.64(<0.001)$ & $0.45(<0.001)$ & \\
\hline$n$ & 29 & 29 & 41 & \\
\hline \multicolumn{5}{|c|}{$t_{2}$ Subsample good comprehension } \\
\hline $\operatorname{ICC}(3,1)$ consistency & 0.49 & 0.55 & 0.46 & 0.50 \\
\hline $\operatorname{ICC}(3,1)$ absolute & 0.43 & 0.40 & 0.36 & 0.40 \\
\hline$p(\mathrm{ICC})$ & 0.016 & 0.007 & 0.009 & \\
\hline Mean difference $(p)$ & $0.43(0.021)$ & $0.68(0.001)$ & $0.45(0.001)$ & \\
\hline$n$ & 18 & 18 & 25 & \\
\hline
\end{tabular}

$p$ (ICC): $p$ value for ICC's; mean difference: mean of QOLself and QOLproxy ( $p$ value based on $t$ test for paired samples)

\section{Agreement between self-reports and proxy measures}

Table 5 shows the results regarding self-proxy agreement using ICC based on consistency and absolute agreement. At $t_{1}$, agreement is only significant for proxy $2(p<0.05)$ and marginally significant for proxy 1 and proxy $3(p<0.10)$. All ICC values are smaller than 0.4 , suggesting poor agreement between proxy scores and self-reports collected at $t_{1}$. In contrast, agreements between the subsample with good comprehension at $t_{1}$ and all proxy measures are significant $(p<0.05)$ with ICC consistency values $\geq 0.4$. Therefore, fair-to-good consistency agreement is suggested for this subpopulation. However, as self-rated QOL scores are systematically higher compared to proxy-rated QOL, absolute agreement is lower and ICCs based on absolute agreement still fall beyond the threshold of 0.4 for fair-to-good agreement in this subsample.

In contrast, all self-proxy agreements based on selfreports measured at $t_{2}$ are significant $(p<0.05)$. The mean value of ICCs across the proxies based on consistency agreement is $>0.4$ with only small differences between the total sample and the subpopulation with good comprehension.
Again, smaller values for the ICCs based on absolute agreement compared to consistency agreement are observed, although even the mean value of absolute agreement reaches the threshold of 0.4 for the subpopulation with good comprehension. The mean absolute agreement for the total sample falls beyond the threshold of 0.4 .

In sum, poor agreement between self and proxy measures was found for self-reports collected at $t_{1}$ with respect to the total sample, whereas self-reports of the subsample with good comprehension at $t_{1}$ and self-reports of the total sample at $t_{2}$ show fair-to-good consistency agreement.

As the ICC's of absolute self-proxy agreement were shown to be lower compared to ICCs based on consistency agreement, systematic mean differences of self-reported QOL compared to proxy-rated QOL could be expected, which is also apparent from the descriptive information given in Table 2.

Table 5 shows the $p$ values for the differences of mean QOL scores between self-rating and proxy rating. The selfrated QOL scores at both time points are significantly higher compared to all three proxy ratings $(p<0.05)$. Further analyses (not shown in Table 5) reveal that no significant differences in the mean QOL scores within the three proxy ratings 
are observed ( $p=0.327-0.667)$. Similarly, no significant differences in the mean scores of self-reported QOL between both time points are found $(p=0.573)$.

To summarize, mean self-rated QOL is consistently higher compared to proxy ratings of QOL. QOL scores of self-reports are stable across both time points, and no significant score differences are observed between the three proxy raters.

\section{Discussion}

Many studies reporting on the Quality of Life of people with intellectual disabilities draw upon proxy ratings versus asking the individuals about their self-reported QOL. Therefore, the goal of this study was to develop an easy-tounderstand sign language version of a standardized quality of life inventory (EUROHIS-QOL), adapted to the visual communication needs of people with prelingual deafness and ID (EUROHIS-QOL ESL).

The easy-to-understand sign language version EUROHIS-QOL ESL can be administered in a time-efficient manner and with high acceptance by individuals who are deaf and have mild-to-moderate ID. $61 \%$ of the people who participated at both time points were rated as having good comprehension by the interviewers. Our finding of increased responsiveness and comprehension with higher IQ is consistent with the previous research [53].

Based on internal consistency as well as on the test-retest method, sufficient reliability $(>0.7)$ of the EUROHIS-QOL ESL measure was confirmed for the total sample of responders. Reliability in the subsample with good questionnaire comprehension was high $(>0.8)$. With respect to validity, significant correlations between self-rated QOL and the Stark-questionnaire measure were confirmed for the total sample of responders at both time points. In contrast, none of the three proxy QOL ratings were significantly correlated with respondents' scores on the Stark measure in the total sample. As with reliability, higher validity was estimated for the subsample with good comprehension. Moreover, two out of the three proxy ratings were significantly correlated with respondents' scores on the Stark measure in the subsample with good comprehension. To avoid a possible inflation of correlations due to common- or mono-method bias, an alternative experimental approach, the "Light Response" was evaluated. Overall, only weak and mostly insignificant associations between QOL measures and the Light response were found. This might be attributed to the higher cognitive demands in understanding the metaphor between brightness of light and well-being. Nevertheless, a marginally significant correlation between the Light response and the
EUROHIS-QOL ESL scores measured at $t_{2}$ and a significant correlation for the subsample with good questionnaire comprehension at $t_{2}$ was confirmed, whereas proxy QOL measures were not significantly correlated with the Light response.

With respect to the consistency agreement between self-reported and proxy-reported QOL, poor concordance (ICC < 0.4) was found for the self-ratings of the total sample at $t_{1}$. However, fair-to-good agreement (ICC $\left.\geq 0.4\right)$ was confirmed for the subsample with good comprehension. Regarding the total sample of responders, fair-togood mean consistency agreement for self-ratings at $t_{2}$ and proxy-reported QOL measured was confirmed. Again, for measures at $t_{2}$, consistency was slightly higher in the subsample with good questionnaire comprehension, but the difference between those with good comprehension and the total sample was less pronounced compared to the measures taken at $t_{1}$.

Unlike consistency-based agreement between self and proxy ratings, absolute agreement was considerably weaker and, except for the subsample with good comprehension at $t_{2}$, classified as poor on the basis of thresholds suggested by Trevethan [50]. Hence, although there is a systematic significant relationship between self- and proxy ratings, the results suggest that this concordance does not necessarily mean absolute agreement of self- and proxy ratings. Our results confirm that self-reported QOL was significantly higher compared to proxy-rated QOL, which is consistent with the results of most of previous studies [10, 19-21]. Nevertheless, it cannot be ruled out, for example, that the systematic difference between self- and proxy-rated QOL is due to acquiescence bias or a higher tendency of individuals with ID to choose extreme or socially desirable answer categories [54]. However, it is also likely that proxies rate QOL of individuals with disabilities based on their own values and expectations, resulting in an underestimation of the proxy-rated QOL [12, $19,55]$. Moreover, proxies may predominately base their estimation on manifest (e.g., bodily conditions or social activities) or communicated information provided by the individuals with disability, which may be poor indicators of the subjective QOL of the rated individuals.

Our results showed somewhat higher estimated validity and consistency agreement for measures taken at $t_{2}$ compared to $t_{1}$. An improvement of data quality associated with repeated measurement is not uncommon and known as a specific type of a panel conditioning effect through cognitive stimulation [56]. Hence, a possible interpretation could be that individuals with ID benefit from repeated survey administration, by learning how to deal with the unfamiliar survey procedure and enhancement of the cognitive process of answering specific types of questions. This interpretation would be consistent with van 
de Vijver and Poortinga [48], who noted that especially "individuals with little test experience can be expected to gain more from repeated test administration". From this perspective, it could be expected that data quality may be improved either through a combination of measures taken from repeated administration, or by implementing practice trails before the final administration.

\section{Limitations}

First, the presented results are based on a small sample size. Although large-scale research in populations with deafness and ID is difficult, replications with larger sample sizes will be needed to confirm the findings from this study. Larger sample size would also be needed to better understand variations in QOL responses and measurement in the highly heterogeneous population of persons who are deaf and have ID. To counteract this limitation, the sample was divided into three groups based on the ability to respond and the level of the comprehension of the questions. However, these subsamples were not large enough to enable more thorough analyses. Not all measures were collected at both time points. Due to the logistical challenges noted previously, proxy ratings were only administered at time point 1 . However, the previous research suggests that Quality of Life is a rather stable parameter [57], and therefore, comparisons of self-rated QOL at $t_{2}$ and proxyrated QOL at $t_{1}$ with a time gap of 6 months seem to be a justified. Questionnaire comprehension was rated by a single interviewer. For future studies, it would be beneficial to have two independent raters, which would enable the estimation of interrater-reliability.

\section{Conclusion}

This study was based on the principle that people with ID should have the opportunity to self-report their quality of life, which also applies to people who are deaf. The QOL ESL, with its simple linguistic structure and choice of basic vocabulary, could be administered to people with deafness and mild-to-moderate ID, and provided reliable and valid results. This opens opportunities to include also individuals who are deaf and have ID themselves into dimensions of quality-of-life research.

Funding Not applicable. Open access funding provided by Johannes Kepler University Linz.

Data availability All data and materials are stored anonymously with the authors.

\section{Compliance with ethical standards}

Conflict of interest The authors declare that they have no conflict of interest.

Ethical approval The study was approved by the Ethical Committee of the Konventhospital Barmherzige Brüder Linz. The ethical approval number is EK 14-08.

Consent to participate All participants were given information about the study in easy-to-understand sign language and gave their informed consent. When applicable, a legal guardian was present at the appointment.

Consent for publication Part of the informed consent was that the results will be used anonymously for scientific research.

Open Access This article is licensed under a Creative Commons Attribution 4.0 International License, which permits use, sharing, adaptation, distribution and reproduction in any medium or format, as long as you give appropriate credit to the original author(s) and the source, provide a link to the Creative Commons licence, and indicate if changes were made. The images or other third party material in this article are included in the article's Creative Commons licence, unless indicated otherwise in a credit line to the material. If material is not included in the article's Creative Commons licence and your intended use is not permitted by statutory regulation or exceeds the permitted use, you will need to obtain permission directly from the copyright holder. To view a copy of this licence, visit http://creativecommons.org/licenses/by/4.0/.

\section{References}

1. United Nations (2006) Convention on the Rights of Persons with Disabilities (CRPD). New York https://www.un.org/development/ desa/disabilities/convention-on-the-rights-of-persons-with-disab ilities/convention-on-the-rights-of-persons-with-disabilities-2. html. Accessed 6 May 2019

2. Verdugo MA, Navas P, Gómez LE, Schalock RL (2012) The concept of quality of life and its role in enhancing human rights in the field of intellectual disability. J Intellect Disabil Res 56(11):10361045. https://doi.org/10.1111/j.1365-2788.2012.01585.x

3. Finlay WML, Lyons E (2002) Acquiescence in interviews with people with mental retardation. Ment Retard 40(1):14-29. https:// doi.org/10.1352/0047-6765(2002)040<0014:AIIWPW>2.0.CO;2

4. Hartley SL, MacLean WE Jr (2006) A review of the reliability and validity of Likert-type scales for people with intellectual disability. J Intellect Disabil Res 50(11):813-827. https://doi.org/10 $.1111 / \mathrm{j} .1365-2788.2006 .00844 . \mathrm{x}$

5. Kravetz S, Katz S, Alfa-Roller I, Yehoshua S (2003) Aspects of theory of mind and self-reports of quality of life by persons with mental retardation. J Develop Phys Disabil 15(2):165-183. https ://doi.org/10.1023/A:1022879401484

6. Matikka LM, Vesala HT (1997) Acquiescence in quality of life interviews with adults who have mental retardation. Ment Retard 35:78-82. https://doi.org/10.1352/00476765(1997)035<0075:AIQIWA>2.0.CO;2

7. Lundy JEB (2002) Age and language skills of deaf children in relation to theory of mind development. J Deaf Stud Deaf Educ 7(1):41-56. https://doi.org/10.1093/deafed/7.1.41

8. Verdugo MA, Schalock RL, Keith KD, Stancliffe RJ (2005) Quality of life and its measurement: important principles and 
guidelines. J Intellect Disabil Res 49(10):707-717. https://doi. org/10.1111/j.1365-2788.2005.00739.x

9. Bertelli M, Brown I (2006) Quality of life for people with intellectual disabilities. Curr Opin Psychiatry 19(5):508-513. https:// doi.org/10.1097/01.yco.0000238479.81528.9f

10. Balboni G, Coscarelli A, Giunti G, Schalock R (2013) The assessment of the quality of life of adults with intellectual disability: the use of self-report and report of others assessment strategies. Res Dev Disabil 34(11):4248-4254. https://doi.org/10.1016/j. ridd.2013.09.009

11. Schalock RL, Bonham GS, Marchand CB (2000) Consumer based quality of life assessment: a path model of perceived satisfaction. Eval Program Plann 23(1):77-87. https://doi.org/10.1016/S0149 -7189(99)00041-5

12. Bertelli MO, Bianco A, Rossi A, Mancini M, La Malfa G, Brown I (2019) Impact of severe intellectual disability on proxy instrumental assessment of quality of life. J Intellect Dev Disabil 44(3):272281. https://doi.org/10.3109/13668250.2017.1350835

13. Schalock RL, Keith KD (1993) Quality of Life Questionnaire Manual. IDS Publishing Corporation, Worthington

14. Reiter S, Bendov D (1996) The self concept and quality of life of two groups of learning disabled adults living at home and in group homes. Br J Develop Disabil 42(83):97-111. https://doi. org/10.1179/bjdd.1996.009

15. Rapley M, Ridgway J, Beyer S (1998) Staff:staff and staff:client reliability of the Schalock \& Keith (1993) quality of life questionnaire. J Intellect Disabil Res 42(1):37-42. https://doi.org/1 0.1046/j.1365-2788.1998.00066.x

16. Beadle-Brown J, Murphy G, DiTerlizzi M (2009) Quality of life for the camberwell cohort. J Appl Res Intellect Disabil 22(4):380-390. https://doi.org/10.111 $1 /$ j.1468-3148.2008.00473.xl

17. Schwartz C, Rabinovitz S (2003) Life satisfaction of people with intellectual disability living in community residences: perceptions of the residents, their parents and staff members. J Intellect Disabil Res 47(2):75-84. https://doi.org/10.1046/j.1365-2788.2003.00436 . $\mathrm{x}$

18. Simões C, Santos S (2016) The Quality of life perception of people with intellectual disability and their proxies. J Intellect Dev Disabil 41(4):311-323. https://doi.org/10.3109/13668 250.2016.1197385

19. Claes C, Vandevelde S, Von Hove G, van Loon J, Verschelden G, Schalock R (2012) Relationship between self-report and proxy ratings on assessed personal quality of life-related outcomes. J Policy Pract Intellect Disabil 9(3):159-165. https://doi.org/10.11 11/j.1741-1130.2012.00353.x

20. Janssen C, Schuengel C, Stolk J (2005) Perspectives on quality of life of people with intellectual disabilities: the interpretation of discrepancies between clients and caregivers. Qual Life Res 14(1):57-69. https://doi.org/10.1007/s11136-004-1692-z

21. Schmidt S, Power M, Green A, Lucas-Carrasco R, Eser E, Dragomirecka E, Fleck M (2010) Self and proxy rating of quality of life in adults with intellectual disabilities: results from the DISQOL study. Res Dev Disabil 31(5):1051-1026. https://doi. org/10.1016/j.ridd.2010.04.013

22. Meuwese-Jongejeugd A, Vink M, van Zanten B, Verschuure H, Eichhorn E, Koopman D, Bernsen R, Evenhuis H (2006) Prevalence of hearing impairment in 1,589 adults with an intellectual disability: cross-sectional population based study. Int J Audiol 45(11):660-669. https://doi.org/10.1080/14992020600920812

23. Fellinger J, Holzinger D, Dirmhirn A, Van Dijk J, Goldberg D (2009) Failure to detect deaf-blindness in a population of people with intellectual disability. J Intellect Disabil Res 53(10):874-881. https://doi.org/10.1111/j.1365-2788.2009.01205.x

24. Glickman N (2007) Do you hear voices? Problems in assessment of mental status in deaf persons with severe language deprivation.
J Deaf Stud Deaf Educ 12(2):127-147. https://doi.org/10.1093/ deafed/enm001

25. Tellegen PJ, Laros JA, Petermann F (2012) SON-R 6-40. Nonverbaler Intelligenztest. Göttingen, Hogrefe

26. Tellegen PJ, Laros JA, Petermann F (2007) SON-R 21/2-7. Nonverbaler Intelligenztest. Göttingen, Hogrefe

27. Schmidt S, Mühlan H, Power M (2006) The EUROHIS-QOL 8-item index: psychometric results of a cross-cultural field study. Eur J Public Health 16(4):420-428. https://doi.org/10.1093/eurpu b/cki155

28. Power M, Harper A, Bullinger M (1998) The World Health Organization WHOQOL-100: tests of the universality of quality of life in fifteen different cultural groups world-wide. Health Psychol 18(5):495-505. https://doi.org/10.1037//0278-6133.18.5.495

29. World Health Organization (1995) WHOQOL-100 The 100 Questions with response scales. Geneva

30. The WHOQOL Group (1998) Development of the World Health Organization WHOQOL BREF quality of life assessment. Psychol Med 28:551-558

31. Angermeyer M, Kilian R, Matschinger H (2000) WHOQOL-100 und WHOQOL-BREF. Handbuch für die deutschsprachige Version der WHO Instrumente zur Erfassung der Lebensqualität. Göttingen

32. Skevington SM, Lotfy M, O'Conell KA (2004) The World Health Organization's WHOQOL-BREF quality of life assessment: psychometric properties and results of the international field trial. A report from the WHOQOL group. Qual Life Res 13(2):229-310. https://doi.org/10.1023/B:QURE.0000018486 .91360 .00

33. Fellinger J, Holzinger D, Dobner U, Gerich J, Lehner R, Lenz G, Goldberg D (2005) An innovative and reliable way of measuring health-related quality of life and mental distress in the deaf community. Soc Psychiatry Psychiatr Epidemiol 40(3):245-250. https://doi.org/10.1007/s00127-005-0862-9

34. Brähler E, Mühlan H, Albani C, Schmidt S (2007) Teststatistische Prüfung und Normierung der deutschen version des EUROHIS-QOL Lebensqualität- index und des WHO-5 Wohlbefindens-Index. Diagnostica 53:83-96. https://doi. org/10.1026/0012-1924.53.2.83

35. Mathias S, Fifer S, Patrick D (1994) Rapid translation of quality of life measures for international clinical trials: avoiding errors in the minimalist approach. Qual Life Res 3(6):403-412. https ://doi.org/10.1007/bf00435392

36. Wild D, Grove A, Martin M, Eremenco S, McElroy S, VerjeeLorenz A, Erikson P (2005) Principles of good practice for the translation and cultural adaptation process for patient-reported outcomes (PRO) measures: report of the ISPOR task force for translation and cultural adaptation. Value Health 8(2):94-104. https://doi.org/10.1111/j.1524-4733.2005.04054.x

37. Inclusion Europe (2016) Information for all, European standards for making information easy to read and understand. https:// easy-to-read.eu/european-standards/. Accessed on 6 May 2019

38. Matausch K, Nietzio A (2011) Easy-to- Read and Plain Language: Defining Criteria and Refining Rules. https://www. w3.org/WAI/RD/2012/easy-to-read/paper11/. Accessed on 6 May 2019

39. Rogers K, Pilling M, Davies L, Belk R, Nassimi-Green C, Young A (2016) Translation, validity and reliability of the British Sign Language (BSL) version of the EQ-5D-5L. Qual Life Res 25(7):1825-1834. https://doi.org/10.1007/s11136-016-1235-4

40. Townsend-White C, Pham AN, Vassos MV (2012) Review: a systematic review of quality of life measures for people with intellectual disabilities and challenging behaviours. J Intellect Disabil Res 56(3):270-284. https://doi.org/10.1111/j.1365-2788.2011.01427 $\mathrm{x}$ 
41. Gerich J, Lehner R (2006) Video computer-assisted interviews for deaf respondents. Field Methods 18(3):267-283. https://doi. org/10.1177/1525822X06287535

42. Claes C, Van Hove G, Van Loon J, Vandevelde S, Schalock RL (2010) Quality of life measurement in the field of intellectual disabilities: eight principles for assessing quality of life-related personal outcomes. Soc Indic Res 98(1):61-72. https://doi. org/10.1007/s11205-009-9517-7

43. Pickard S, Knight S (2005) Proxy evaluation of health-related quality of life: a conceptual framework for understanding multiple proxy perspectives. Med Care 43(5):493-499. https://doi. org/10.1097/01.mlr.0000160419.27642.a8

44. McPhail S, Beller E, Haines T (2008) Two perspectives of proxy reporting of health-related quality of life using the Euroqol-5D, an investigation of agreement. Med Care 46(11):1140-1148. https ://doi.org/10.1097/MLR.0b013e31817d69a6

45. Hardt J (2015) A new questionnaire for measuring quality of life - the Stark QoL. Health Qual Life Outcomes 13:174. https://doi. org/10.1186/s12955-015-0367-5

46. Podsakoff PM, MacKenzie SB, Podsakoff NP (2012) Source of method bias in social science research and recommendations on how to control it. Annu Rev Psychol 63:539-569. https://doi. org/10.1146/annurev-psych-120710-100452

47. Ortiz deGuinea A, Titah R, Leger P-M (2013) Measure for measure: a two study multi-trait multi-method investigation of construct validity in IS research. Comput Human Behav 29(3):833844. https://doi.org/10.1016/j.chb.2012.12.009

48. Van de Vijver FJR, Poortinga YH (1997) Towards an integrated analysis of bias in cross-cultural assessment. Eur J Psychol Assess 13(1):29-37. https://doi.org/10.1027/1015-5759.13.1.29
49. Shrout PE, Fleiss JL (1979) Intraclass correlations: uses in assessing rater reliability. Psychol Bull 86(2):420-428. https://doi. org/10.1037/0033-2909.86.2.420

50. Trevethan R (2017) Intraclass correlation coefficients: clearing the air, extending some cautions, and making some requests. Health Serv Outcomes Res Methodol 17:127-143. https://doi. org/10.1007/s10742-016-0156-6

51. Fleiss JL (1986) The design and analysis of clinical experiments. John Wiley \& Sons, New York

52. Nunnally JC, Bernstein IH (1994) Psychometric Theory, third edition

53. Sigelman CK, Elias SF, Danker P (1980) Interview behavior of mentally retarded adults as predictors of employability. J Appl Psychol 65(1):67-73. https://doi.org/10.1037/0021-9010.65.1.67

54. Heal LW, Sigelman CK (1990) Methodological issues in measuring the quality of life of individuals with mental retardation. In: Schalock RL (ed) Quality of life: perspectives and issues. USA. American Association of Mental Retardation, Washington, pp 161-176

55. Stancliff RJ (1999) Proxy respondents and the reliability of the QOL-Q Empowerment factor. J Intellect Disabil Res 43(3):185193. https://doi.org/10.1046/j.1365-2788.1999.00194.X

56. Sturgis P, Allum N, Brunton-Smith I (2009) Attitudes over time: the psychology of panel conditioning. In: Lynn P (ed) Methodology of longitudinal surveys. GB. Wiley, Chichester, pp 113-126

57. Schimmack U, Oishi S (2005) The influence of chronically and temporarily accessible information on life satisfaction judgement. J Pers Soc Psychol 89(3):395-406. https://doi. org/10.1037/0022-3514.89.3.395 